\title{
Severity of obstructive airways disease by age 2 years predicts asthma at 10 years of age
}

\author{
C S Devulapalli, ${ }^{1,2}$ K C L Carlsen, ${ }^{1,3}$ G Håland, ${ }^{1}$ M C Munthe-Kaas, ${ }^{1,3}$ M Pettersen, ${ }^{2}$ \\ P Mowinckel, ${ }^{1} \mathrm{~K}-\mathrm{H}$ Carlsen ${ }^{2,3}$
}

${ }^{1}$ Department of Paediatrics, Division of Woman and Child, Ullevål University Hospital, Oslo, Norway; ${ }^{2}$ Voksentoppen, Department of Paediatrics, Rikshospitalet-Radiumhospitalet Medical Centre, Oslo, Norway;

${ }^{3}$ The Medical Faculty, University of Oslo, Oslo, Norway

Correspondence to: Dr K-H Carlsen, Voksentoppen, Department of Paediatrics, Rikshospitalet-Radiumhospitalet Medical Centre, Oslo, University of Oslo, N0-0791 Oslo, Norway; k.h.carlsen@medisin.uio.no

The study is performed within the ORAACLE (the Oslo Research Group of Asthma and Allergy in Childhood; the Lung and Environment), a member of GA²LEN (Global Allergy and Asthma European Network).

Received 9 February 2006 Accepted 12 June 2007 Published Online First 5 July 2007

\section{ABSTRACT}

Background: Predicting school-age asthma from obstructive airways disease (OAD) in early life is difficult, even when parental and children's atopic manifestations are taken into consideration.

Objective: To assess if the severity of $O A D$ in the first 2 years of life predicts asthma at 10 years of age.

Methods: From a nested case control study within the Environment and Childhood Asthma study, 233 2-year-old subjects with recurrent ( $\geqslant 2$ episodes) bronchial obstruction $(\mathrm{rBO}+)$ and 216 subjects without bronchial obstruction (rBO-) underwent clinical examination, parental interview, treadmill test and metacholine bronchial hyperresponsiveness (BHR) measurement at 10 years. A severity score at 2 years was calculated by frequency, persistence of bronchial obstruction and hospital admissions because of OAD.

Main outcomes: Current asthma at 10 years (asthma with symptoms and/or asthma medication during the past year and/or positive treadmill test). Secondary outcome was metacholine BHR at 10 years.

Results: Compared with rBO - subjects, adjusted odds ratio $(95 \% \mathrm{Cl})$ of current asthma among $\mathrm{rBO}+$ was 7.9 $(4.1,15.3)$, and among rBO+ with a severity score of $>5$, $20.2(9.9,41.3)$. In receiver operated characteristic analysis, positive and negative predictive values demonstrated the applicability and value of the score, with an optimal cut-off at severity score 5 . Children with severity score $>5$ had severe BHR more often $\left(\mathrm{PD}_{20}\right.$ metacholine $<1 \mu \mathrm{mol})$ than children with a lower or 0 score $(\mathrm{p}=0.0041)$.

Conclusion: Using a simple scoring system, a high severity score of $O A D$ by 2 years of age is a strong risk factor for, and may predict, current asthma at 10 years of age.

The majority of school children with asthma have asthma-like symptoms during the first few years of life. However, predicting asthma at school age from wheezing illness in early life is challenging as the aetiology of wheezy lower respiratory tract disease in early childhood is heterogeneous. ${ }^{1-3}$ Children with severe asthma are more likely to require emergency medical visits, hospital admissions and often have reduced quality of life. ${ }^{4}$ Early life events may influence later respiratory illness, ${ }^{5}$ and we have recently reported the association between reduced lung function at birth and current asthma and severe bronchial hyperresponsiveness at 10 years of age. ${ }^{6}$

Clough and colleagues ${ }^{7}$ developed models to predict 12 months of persistent wheezing in infant wheezers, with maximal predictive value of $78 \%$, including personal atopy, parental atopy, age and cytokine studies. From the Tucson Children's Respiratory Study, Castro-Rodriguez et al ${ }^{8}$ developed two clinical indices at 3 years of age to define risk of asthma at school age. They found active asthma on at least one occasion between 6 and 13 years in $76 \%$ and $59 \%$ of children with their positive stringent and loose index models, respectively. Their indices included characteristics of wheezing at 0-3 years, doctor diagnosed parental asthma or eczema, eosinophilia or allergic rhinitis. However, despite the increased risk of later asthma among hospital admitted young children with obstructive airways disease (OAD), ${ }^{9}$ none of these studies $^{710}$ included severity of (frequency and/or persistence) and/or hospital admissions for $\mathrm{OAD}$ in their models.

Early identification of children at risk of persistent asthma in childhood may improve follow-up of children at risk. The main objective of the present study was to assess if the severity of $\mathrm{OAD}$ during the first 2 years of life predicts current (ongoing) asthma at 10 years of age.

\section{METHODS AND SUBJECTS}

\section{Study design and subjects}

The present study is part of the 10 year follow-up of the Environment and Childhood Asthma study in Oslo. ${ }^{11}$ Briefly, a cohort of 3754 newborns was established at birth in Oslo over 15 months starting from 1 January 1992 when parents completed the first of five half yearly questionnaires until the child's second birthday. Questions included family history of allergic and other diseases, environmental exposures (including parental smoking habits and pet keeping), health of the child (respiratory, allergic, skin as well as general diseases) and details of any medical treatment. ${ }^{11}$ The study was approved by the Regional Committee for Medical Ethics and the Norwegian data inspectorate. Written informed consent was obtained from parents of all subjects.

A nested case control study was established based on the children participating in the birth cohort study ${ }^{11} 12$ to perform detailed examinations of children with recurrent ( $\geqslant 2$ episodes of or $\geqslant 4$ weeks (persistent)) doctor confirmed bronchial obstruction (BO) by their second birthday (cases or $\mathrm{rBO}+)(\mathrm{n}=306)$ and the child born closest in time without $\mathrm{BO}$ by 2 years of age $(\mathrm{rBO}-)(\mathrm{n}=306)$. Recruitment strategies to identify all $\mathrm{rBO}+$ children have been reported previously. ${ }^{11}{ }^{12}$

The 2 year clinical visit was attended by $516 / 612$ eligible children, $265 \mathrm{rBO}+$ and $251 \mathrm{rBO}-$ children, respectively (fig 1). 


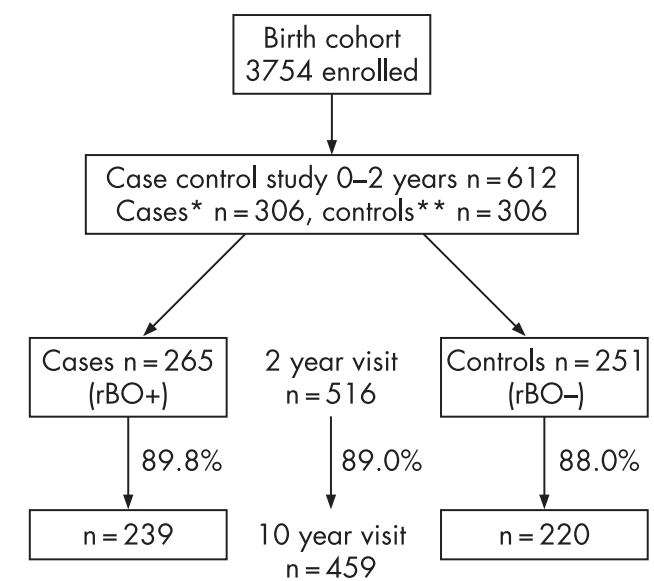

Figure 1 The Environment and Childhood Asthma study in Oslo; subjects from birth to 10 years in the present study. Cases* $(\mathrm{rBO}+)$ were defined as children who had at least two episodes or a minimum of 4 weeks persisting, doctor confirmed, bronchial obstruction and controls $^{* *}(\mathrm{rBO}-)$ were age matched children without bronchial obstruction by 2 years of age. Sufficient data were available for assessment of severity score at 2 years as well as current asthma at 10 years of age in 233/239 rBO+ children and 216/220 rBO- children.

The present study reports the results from the 10 year followup study of the nested case control population only, with a follow-up rate of $89 \%$, including $239 \mathrm{rBO}+$ and $220 \mathrm{rBO}-$ subjects (fig 1). The 459 attendees and the 57 non-attendees did not differ significantly in relation to gender, parental atopy, age, weight or height at 2 years (data not shown). However, because of insufficient data at 2 and/or 10 years in 10 children, the present study included the 449 children $(233 \mathrm{rBO}+$ and 216 $\mathrm{rBO}$ - subjects) with complete data to calculate severity score at 2 years and current asthma at 10 years (fig 1).

\section{Two year clinical visit}

A parental structured interview was performed by the study doctor, including details of diseases of the index child and primary family members, infections, environmental exposures, housing, socioeconomic factors and any type of medical treatment. Severity of $\mathrm{OAD}$ was assessed by the questions: "has the child ever had wheezing and/or shortness of birth?", if yes, "the number of episodes with wheezing" and/or "the number of months with persistent wheezing" and "was the child ever admitted to hospital due to wheezing?" and if yes, "the number of hospital admissions for wheezing".

The skin prick test was performed according to the Nordic standard $^{13}$ to the following allergens: cow's milk, and the following standardised (ALK SQ): egg white, dermatophagoides pteronyssinus, timothy grass, cat dander, dog dander, silver birch, mugwort and cladosporium herbarum, as well as negative control solution and histamine control $(10 \mathrm{mg} / \mathrm{ml})$. Sensitisation was regarded as positive with an allergen weal of at least half the size of the histamine weal. Parental atopy by 2 years of age was defined as asthma and/or rhinoconjunctivitis reported in at least one parent.

\section{Severity score}

A severity score was calculated based on the clinical criteria present from 0 to 2 years of age: number of episodes of $\mathrm{BO}$, number of months with persistent $\mathrm{BO}$ and number of hospital admissions due to $\mathrm{BO}$ (fig 2). Maximum score for an individual was 12 . Two $\mathrm{rBO}$ - subjects had a severity score of 1 whereas the remaining subjects $(n=214)$ had a severity score of 0 . The severity score was also calculated for patients at 12 months of age based on questionnaire data obtained every 6 months from birth to 2 years of age.

\section{Ten year follow-up visit}

At the 10 year visit, ${ }^{14}$ the study doctors conducted parental structured interviews regarding the child's symptoms of asthma and asthma management, including validated questions from the International Study of Asthma and Allergies in Children.

Forced expiratory flow volume loops were measured according to European standards ${ }^{15}$ (reference values of Zapletal and colleagues $^{16}$ with a SensorMedics Vmax 20c (SensorMedics Diagnostics, Yorba Linda, California, USA)).

Bronchial hyperresponsiveness (BHR) was measured after withholding short and long acting $\beta 2$ agonists for at least 12 and $48 \mathrm{~h}$, respectively, and leucotriene antagonists for $72 \mathrm{~h}$, by methacholine challenge test performed the first day and by exercise challenge (treadmill run) within 1 week.

Methacholine challenge test was performed according to international guidelines ${ }^{17}$ by inhalation of doubling doses of methacholine, nebulised by the Spira nebuliser (Spira Respiratory Care Centre Ltd, Hämeenlinna, Finland), until reaching a cumulated dose of methacholine causing a reduction in forced expiratory volume in the first second $\left(\mathrm{FEV}_{1}\right)$ of $20 \%$ $\left(\mathrm{PD}_{20}\right.$ methacholine) or reaching the maximum cumulated dose $\left(\mathrm{PD}_{20}\right)$ of $22.4 \mu \mathrm{mol}$ methacholine.

A standardised exercise challenge test included running for 68 min on a motor driven treadmill (Woodway; Woodway $\mathrm{GmbH}$, Weil am Rhein, Germany) (inclination of 5.5\%), with increasing speed during the first 2 min to reach a heart rate of $95 \%$ of estimated maximum. ${ }^{18} \mathrm{FEV}_{1}$ was measured before, and $3,6,10$ and 15 min after running. The exercise challenge test was considered positive with $\geqslant 10 \%$ fall of baseline $\mathrm{FEV}_{1} 3-$ 20 minutes after running ceased.

The skin prick test performed the first day of the 10 year follow-up visit is not reported, as outcome is related only to the events during $0-2$ years of age.

\section{Outcomes}

The main outcome was current asthma at 10 years of age (table 1). ${ }^{14}$ Secondary outcome was non-specific BHR to metacholine $\left(\mathrm{PD}_{20}\right)$.

\section{Statistical analysis}

Continuous variables are presented as mean (SD) and binary variables as counts with percentage. Two sample $t$ tests and Pearson's $\chi^{2}$ test were used to assess differences between $\mathrm{rBO}+$ and $\mathrm{rBO}-$ and subjects with and without current asthma for continuous and categorical variables, respectively.

The risk of current asthma at 10 years of age was assessed using logistic regression analysis comparing $\mathrm{rBO}+$ subjects with severity scores $1-12$ and $\mathrm{rBO}$ - subjects. Results are given as odds ratios (OR) with 95\% CI. The appropriateness of the logistic model was assessed using Hosmer and Lemeshow goodness of fit statistic. ${ }^{19}$ Dfbetas (defined as the change in the estimated parameters when the individual observation is deleted) and C-bar (a scalar measure of the influence of individual observations) statistics were used to assess the influence of an individual observation on each estimated parameter in the fitted model. Difference in deviance and $\chi^{2}$ were used to detect ill-fitted observations. ${ }^{19}$ Linearity of severity score as a continuous variable was assessed using Hosmer's 
Figure 2 Severity score for obstructive airways disease. Criteria for severity score by 2 years of age. B0, bronchial obstruction. Maximum score is 12 .

\begin{tabular}{|c|c|c|c|c|c|}
\hline $\mathrm{BO}$ episodes and/or persisting $\mathrm{BO}$ & Points & & No. of hospital adm. for $B O$ & Points & \\
\hline $\begin{array}{l}\text { None } \\
1-2 \text { episodes or } 1 \text { month persistiong } \\
3-4 \text { episodes } \\
2-3 \text { months persisting } \\
5-6 \text { episodes } \\
4-6 \text { months persisting } \\
>6 \text { episodes or }>6 \text { months persisting }\end{array}$ & $\begin{array}{l}0 \\
1 \\
2 \\
3 \\
4 \\
5 \\
6\end{array}$ & + & $\begin{array}{l}\text { None } \\
1 \\
2 \\
>2\end{array}$ & $\begin{array}{l}0 \\
2 \\
4 \\
6\end{array}$ & $=$ Severity score $(0-12)$ \\
\hline
\end{tabular}

procedure. ${ }^{19}$ It was not feasible to perform logistic regression separately based on gender because of questionable model fit. Atopic dermatitis and allergic skin sensitisation at 2 years were included in the model as possible confounders.

Receiver operated characteristic (ROC) analysis was performed using the severity score $1-12$ at 2 years and classification by current asthma at 10 years of age as clinical outcome. Sensitivity (probability (\%) of a positive test result when the disease is present), specificity (probability (\%) of a negative test result when the disease is not present), positive predictive value (probability (\%) that the disease is present with a positive test) and negative predictive value (probability (\%) that the disease is not present with a negative test) of severity scores were calculated. The prediction models of loose and stringent indices suggested by Castro-Rodriguez and colleagues ${ }^{8}$ were approximated to similar data in the present study, and predictive capacities were compared with our severity score.

A $p$ values of $\leqslant 0.05$ was considered statistically significant. Calculations were performed with Statistical Package for Social Sciences (SPSS) V.12.0 for Windows and Statistical Analysis System (SAS) V.9.13.

\section{RESULTS}

Baseline demographic data and parental atopy for the 449 children (242 boys and 207 girls) included in the study (fig 1) were similar for the $\mathrm{rBO}+$ children with $(\mathrm{n}=233)$ and without $(\mathrm{n}=6)$ and for the $\mathrm{rBO}-$ children with $(\mathrm{n}=216)$ and without $(\mathrm{n}=4)$ sufficient data to assess current asthma (data not shown). Mean (SD) age at the 10 year visit was 10.3 (0.7) years.

At the 2 year visit, $\mathrm{rBO}+$ subjects were slightly younger, more frequently reported parental atopy (both $p<0.001)$ and atopic dermatitis $(p=0.022)$ and were slightly shorter $(p=0.005)$ than $\mathrm{rBO}$ - children (table 2). At 10 years, weight, length and age did not differ significantly between $\mathrm{rBO}+$ and $\mathrm{rBO}-$ subjects (table 2).

Table 1 Definitions of the main outcome in the present study Outcome

Asthma was defined as at least two of the following three criteria positive:

(1) Dyspnoea, chest tightness and/or wheezing from 0 to 3 years and/or from 4 to 10 years of age

(2) Doctor diagnosed asthma

(3) Used asthma medication (inhaled corticosteroids, $\beta 2$ agonists, sodium cromoglycate, leucotriene antagonists and/or aminophylline) at 0-3 years and/or 410 years of age

Current asthma was defined as asthma (see above) plus at least one of the following criteria positive:

(1) Dyspnoea, chest tightness and/or wheezing during the past 12 months

(2) Use of asthma medication during the past 12 months

(3) Positive exercise test

\section{Current asthma at $\mathbf{1 0}$ years of age}

Current asthma at 10 years was significantly more frequent among $\mathrm{rBO}+(\mathrm{n}=85,36.5 \%)$ compared with $\mathrm{rBO}-$ subjects $(\mathrm{n}=12,5.6 \%)(\mathrm{p}<0.001) . \mathrm{rBO}+$ children with compared with those without current asthma were not significantly different with respect to age, weight or height at 2 and 10 years, or atopic dermatitis, parental atopy or allergic skin sensitisation at 2 years (table 3 ). However, $\mathrm{rBO}+$ children with current asthma (at 10 years) were more often hospitalised due to $\mathrm{BO}$ by 2 years of age $(p=0.01)$ (table 3$)$ than $\mathrm{rBO}+$ children without current asthma. More boys than girls had current asthma at 10 years $(p=0.05)$ (table 3$)$.

\section{Severity score}

The severity score distribution at 2 years is shown in fig 3 . The mean $(95 \% \mathrm{CI})$ severity score of all $\mathrm{rBO}+$ subjects at 2 years of age was $4.6(4.2,5.0)$, significantly higher among $\mathrm{rBO}+$ children who developed current asthma $(5.5(4.9,6.1))$ compared with $\mathrm{rBO}+$ children without current asthma $(4.0(3.6,4.5) ; \mathrm{p}<0.001)$ (table 3 ). The mean severity score at 12 months of age among $\mathrm{rBO}+$ subjects was $1.04(0.81,1.27)$.

\section{Risk of current asthma}

Based on analysis of all children $(n=449)$, a linear association was found for severity score as a predictor for current asthma at 10 years; the OR for a 1 point increase in severity score was 1.35 $(1.25,1.45)$ and for a 2 point increase in severity score 1.82 $(1.57,2.11)$.

The unadjusted $\mathrm{OR}$ and adjusted $\mathrm{OR}$ for current asthma among all $\mathrm{rBO}+$ children compared with $\mathrm{rBO}-$ children were 9.8 (5.1, 18.5) and 7.9 (4.1, 15.3), respectively (adjusted for gender, parental atopy and atopic eczema by 2 years of age as well as allergic skin sensitisation at the 2 year visit). Compared

Table 2 Characteristics of the subjects $(n=449)$ in the present study

\begin{tabular}{|c|c|c|c|}
\hline Characteristics & $\begin{array}{l}\text { rBO+ } \\
(\mathrm{n}=233)\end{array}$ & $\begin{array}{l}\mathrm{rBO}- \\
(\mathrm{n}=216)\end{array}$ & p Value \\
\hline Boys & $140(60.1)$ & $102(47.2)$ & 0.006 \\
\hline Age at 2 y visit (months) & $26.0(2.8)$ & $27.7(3.8)$ & $<0.001$ \\
\hline Age at $10 \mathrm{y}$ visit (years) & $10.3(0.7)$ & $10.3(0.8)$ & 0.58 \\
\hline Weight at 2 y visit $(\mathrm{kg})$ & $13.4(1.5)$ & $13.4(1.6)$ & 0.057 \\
\hline Weight at 10 y visit $(\mathrm{kg})$ & $37.8(7.9)$ & $36.8(7.6)$ & 0.17 \\
\hline Height at 2 y visit $(\mathrm{cm})$ & $89.1(3.8)$ & $90.2(4.2)$ & 0.005 \\
\hline Height at $10 \mathrm{y}$ visit $(\mathrm{cm})$ & $143.7(7.2)$ & $143.0(7.5)$ & 0.33 \\
\hline Parental atopy reported by 2 y of age $\mathrm{e}^{*}$ & $129(55.4)$ & $64(29.67)$ & $<0.001$ \\
\hline Atopic dermatitis by $2 \mathrm{y}$ & $88(37.9)$ & $60(27.8)$ & 0.022 \\
\hline Allergic sensitisation by $2 y^{\dagger}$ & $22(9.9)$ & $17(8.1)$ & 0.52 \\
\hline
\end{tabular}

$\mathrm{rBO}+$ children had $\geqslant 2$ episodes or $\geqslant 4$ weeks persistent, doctor confirmed, bronchial obstruction (BO) by 2 years of age. rBO - subjects had no symptoms or signs of BO by 2 years.

Data are presented as $\mathrm{n}(\%)$ or mean (SD).

*Parental atopy: asthma and/or allergic rhinitis reported in at least one parent. $\uparrow$ Allergic skin sensitisation considered positive with $\geqslant 1$ positive skin prick test to common allergens. 
Table 3 Characteristics of children with recurrent bronchial obstruction $(\mathrm{rBO}+)$ by 2 years of age related to the presence of current asthma at 10 years $(n=233)$

\begin{tabular}{|c|c|c|c|}
\hline \multirow[b]{2}{*}{ Characteristics } & \multirow{2}{*}{$\begin{array}{l}\text { Current asthma } \\
\text { Yes }(n=85)\end{array}$} & \multirow[b]{2}{*}{$\overline{\text { No }(n=148)}$} & \multirow[b]{2}{*}{ p Value } \\
\hline & & & \\
\hline Boys & $58(68.2)$ & $82(55.4)$ & 0.054 \\
\hline Age at 2 y visit (months) & $26.0(3.0)$ & $26.0(2.7)$ & 0.98 \\
\hline Age at 10 y visit (y) & $10.3(0.7)$ & $10.4(0.7)$ & 0.22 \\
\hline Weight at 2 y visit $(\mathrm{kg})$ & $13.5(1.7)$ & $13.4(1.4)$ & 0.91 \\
\hline Weight at 10 y visit $(\mathrm{kg})$ & $38.7(8.7)$ & $37.3(7.4)$ & 0.22 \\
\hline Height at 2 y visit $(\mathrm{cm})$ & $89.4(4.2)$ & $88.9(3.6)$ & 0.45 \\
\hline Height at 10 y visit $(\mathrm{cm})$ & $143.1(7.3)$ & $144.1(7.1)$ & 0.35 \\
\hline Atopic dermatitis by 2 y & $38(44.7)$ & $50(34.0)$ & 0.11 \\
\hline Parental atopy by $2 \mathrm{y}^{*}$ & $51(60.0)$ & $78(52.7)$ & 0.28 \\
\hline Allergic skin sensitisation at $2 \mathrm{y}$ visit $†$ & $11(13.6)$ & $11(7.7)$ & 0.16 \\
\hline $\begin{array}{l}\text { Hospital admissions due to bronchial } \\
\text { obstruction } 0-2 \text { y (No of children) }\end{array}$ & $39(45.9)$ & $43(29.1)$ & 0.01 \\
\hline $\begin{array}{l}\text { No of hospital admissions due to } \\
\text { bronchial obstruction } 0-2 \text { y }\end{array}$ & $0.8(0.5-1.0)$ & $0.4(0.3-0.6)$ & 0.014 \\
\hline Severity score at $2 y$ & $5.5(4.9-6.1)$ & $4.0(3.6-4.5)$ & $\mid<0.001$ \\
\hline
\end{tabular}

For definition of current asthma, see table 1.

Data are presented as number (\%) or mean (SD). Severity scores and number of hospital admissions are presented as mean (95\% Cl).

*Parental atopy: asthma and/or allergic rhinitis reported in at least one parent.

$\dagger$ Allergic skin sensitisation considered positive with $\geqslant 1$ positive skin prick test to common allergens.

with $\mathrm{rBO}$ - children, the adjusted $\mathrm{OR}$ for current asthma was $20.2(9.9,41.3)$ for $\mathrm{rBO}+$ children with severity scores of $6-12$ at 2 years of age. Among $\mathrm{rBO}+$ children, hospitalisation due to $\mathrm{BO}$ by 2 years of age caused only a slight increased risk of current asthma (OR $2.0(1.1,3.7)$ ). By using the severity score calculated at the age of 12 months, the adjusted OR for current asthma at 10 years was 1.30 (1.11-1.52) (adjusted for gender, parental atopy) for a 1 point increase in severity score.

The ROC analysis for severity score at 2 years classified by current asthma at 10 years (curve not shown) revealed an area under the curve of 0.78 (95\% CI 0.73, 0.83; p<0.0001). Adjusted $\mathrm{OR}$ and the results of the ROC analysis are shown in table 4 for each step of severity score, with sensitivity, specificity, positive and negative predictive values for current asthma. A score $<3$ and $>5$ had low and high specificity, respectively, for current asthma at 10 years (table 4).

The ROC analysis for severity score at 12 months, classified by current asthma at 10 years, revealed an area under the curve of $0.59(0.54,0.64 ; p=0.007)$. However, with a cut-off value of severity score at 12 months set to 2 (identified as the best value), sensitivity was only $16.8(9.9,25.9)$, specificity 94.3 $(91.3,96.5)$, with a positive predictive value of 44.4 and negative predictive value of 80.6 .

The predictive capacities for current asthma at 10 years of age compared with control children assessed by the stringent and loose indices reported by Castro-Rodriguez et al (originally calculated for children at the age of 3 years $)^{8}$ were applied to comparable data in the present study, and the results are reported in table 4 . Using a cut-off value above 5 in the present severity score at 2 years of age gave a higher positive predictive value (54.3), but similar negative predictive value (86.8) compared with the applied loose (87.7) and stringent (87.4) indices (table 4).

\section{Bronchial hyperresponsiveness}

Children with high severity scores at 2 years of age (above 5) had severe $\mathrm{BHR}\left(\mathrm{PD}_{20}\right.$ metacholine $\left.<1 \mu \mathrm{mol}\right)$ significantly more often and mild or no $\mathrm{BHR}\left(\mathrm{PD}_{20}\right.$ metacholine $\left.>8 \mu \mathrm{mol}\right)$

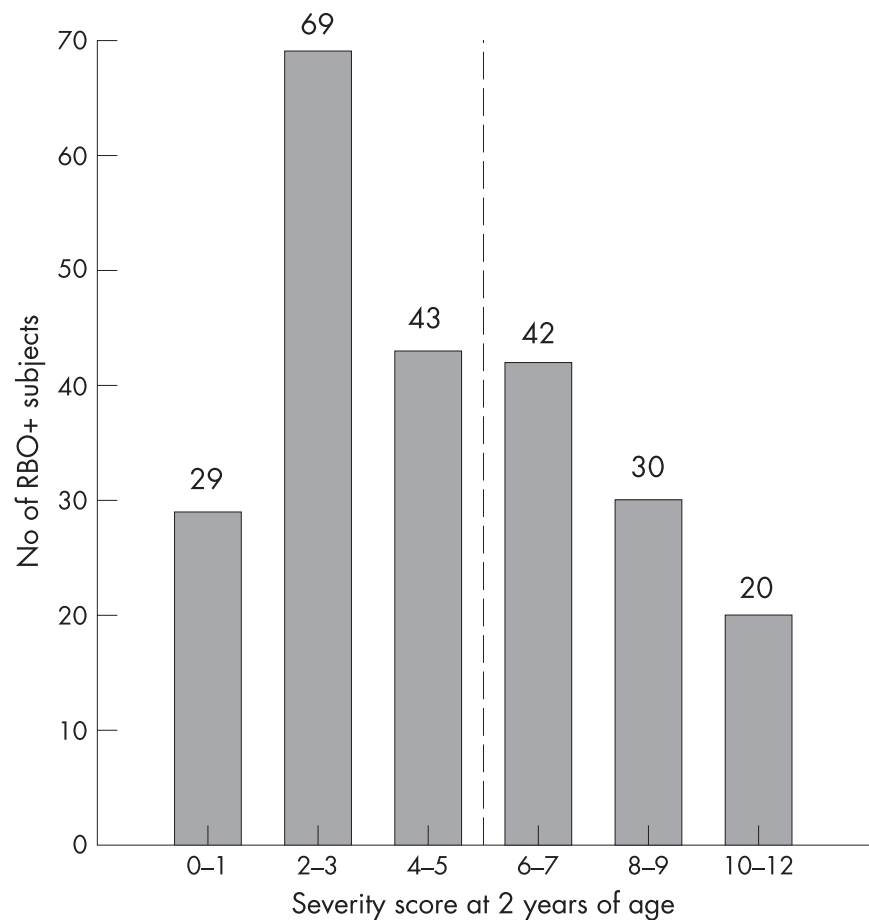

Figure 3 Distribution of severity score in children with recurrent bronchial obstruction $(\mathrm{rBO}+)$ at the age of 2 years $(n=233)$.

significantly less often compared with children with a severity score of 0 (control children) $(p=0.0041)$ (table 5).

\section{DISCUSSION}

The present study demonstrates that a simple asthma severity score based on frequency and persistence of $\mathrm{BO}$ and hospitalisations for $\mathrm{BO}$ during the first 2 years of life predicts a higher risk for current asthma at 10 years of age. The almost linear association between severity score at 2 years and current asthma at 10 years suggests that prediction may be relevant for individual subjects, as well as on a group level.

Compared with the severity score at 2 years, a severity score calculated at 12 months of age, although a significant risk factor, had a poor predictive capability for current asthma 9 years later.

The high risk for current asthma at 10 years in children with higher severity scores at 2 years of age (mostly above 5) compared with children with no $\mathrm{BO}$ by 2 years of age, exceeds previously published reports. ${ }^{7810}$ A severity score of 5 is not infrequent, reflecting two hospital admissions with one additional obstructive episode, or alternatively 5-6 episodes of $\mathrm{BO}$ with 1 month of persisting symptoms.

Dodge et $a l^{10}$ found ORs of 2.1 and 7.2 of having asthma up to 11 years in children who wheezed compared with non-wheezers at 1-2 years and 3-4 years of age, respectively. Although only among preschool children, Clough and coworkers ${ }^{7}$ found after 12 months of follow-up of 3-36-month-old children, that wheeze was more likely to persist in older, atopic infants with biparental atopy, and they detected asthma requiring prophylactic antiasthmatic treatment in $49.5 \%$ of children.

As one of few studies with reported clinical indices to predict asthma beyond 1-2 years, the Tucson study ${ }^{8}$ employed factors from 0 to 3 years of age to predict asthma at school age, including early wheeze and other allergic diseases, parental atopic disease and blood eosinophil count. The loose and 
Table 4 Odds ratio, sensitivity, specificity, positive and negative predictive values for predicting current asthma at 10 years of age in subjects at 2 years with severity scores at 2 years of age from 1 to 12 , as well as approximated indices, as suggested by Castro-Rodriguez et al applied to our dataset ${ }^{8}$

\begin{tabular}{|c|c|c|c|c|c|}
\hline & $\begin{array}{l}\text { Odds ratio } \\
\text { (95\% CI) }\end{array}$ & $\begin{array}{l}\text { Sensitivity (\%) } \\
(95 \% \mathrm{CI})\end{array}$ & $\begin{array}{l}\text { Specificity (\%) } \\
\text { (95\% CI) }\end{array}$ & $\begin{array}{l}\text { PPV (\%) } \\
(95 \% \mathrm{CI})\end{array}$ & $\begin{array}{l}\text { NPV (\%) } \\
(95 \% \mathrm{CI})\end{array}$ \\
\hline Severity score 1 & $9.8(5.1,18.5)$ & $87.6(79.6,92.8)$ & $58.0(52.7,63.0)$ & $36.5(30.6,42.8)$ & $94.4(90.5,96.8)$ \\
\hline Severity score 2 & $8.0(4.6,13.9)$ & $81.4(72.6,87.9)$ & $64.5(59.4,69.3)$ & $38.7(32.3,45.6)$ & $92.7(88.7,95.3)$ \\
\hline Severity score 3 & $5.2(3.2,8.5)$ & $62.9(53.0,71.8)$ & $75.6(70.8,79.8)$ & $41.5(33.8,49,6)$ & $86.1(83.9,91.3)$ \\
\hline Severity score 4 & $6.0(3.7,9.7)$ & $61.9(51.9,70.9)$ & $78.7(74.1,82.6)$ & $44.4(36.3,52.9)$ & $88.2(84.2,91.3)$ \\
\hline Severity score 5 & $8.0(4.8,13.2)$ & $55.6(45.8,65.2)$ & $86.4(82.4,89.6)$ & $52.9(43.3,62.3)$ & $87.6(83.7,90.7)$ \\
\hline Severity score 6 & $7.9(4.7,13.1)$ & $51.5(41.7,61.2)$ & $88.1(84.3,91.1)$ & $54.3(44.2,64.1)$ & $86.8(82.9,90.0)$ \\
\hline Severity score 7 & $4.8(2.6,8.8)$ & $26.8(19.0,36.4)$ & $92.9(89.7,95.1)$ & $51.0(37.7,64.1)$ & $82.2(78.1,85.6)$ \\
\hline Severity score 8 & $4.5(2.5,8.4)$ & $25.8(18.1,35.3$ & $92.9(89.7,95.1)$ & $50.0(36.6,63.4)$ & $82.0(77.9,85.4)$ \\
\hline Severity score 9 & $4.8(2.9,11.5)$ & $12.4(7.2,20.4)$ & $97.2(94.9,98.4)$ & $54.5(34.7,73.1)$ & $80.1(76.0,83.3)$ \\
\hline Severity score 10 & $3.9(1.6,9.7)$ & $10.3(5.7,19.7)$ & $97.2(94.9,98.5)$ & $50.0(29.9,70.1)$ & $79.7(75.7,83.3)$ \\
\hline Severity score 11 & $5.6(0.91,33.9)$ & $3.1(1.1,8.7)$ & $99.4(98.0,99.8)$ & $60.0(23.1,88.2)$ & $78.8(74.8,82.4)$ \\
\hline Severity score 12 & $3.7(0.51,26.5)$ & $2.1(0.6,7.2)$ & $99.4(98.0,99.8)$ & $50.0(15.0,85.0)$ & $78.7(74.6,82.2)$ \\
\hline Positive stringent index ${ }^{*}$ & $6.4(3.9-10.4)$ & $56.7(46.8-66.1)$ & $83.0(78.7-86.5)$ & $47.8(38.9-56.9)$ & $87.4(83.4-90.6)$ \\
\hline Positive loose index* & $5.6(3.5-9.0)$ & $59.8(49.8-69.0)$ & $79.0(74.4-82.9)$ & $43.9(35.8-52.5)$ & $87.7(83.6-90.9)$ \\
\hline
\end{tabular}

${ }^{*}$ Data in the present study have been approximated to the criteria used in asthma indices (stringent and loose) suggested by Castro-Rodriguez et al. ${ }^{8}$

NPV, negative predictive value; PPV, positive predictive value.

stringent indices developed by Castro-Rodriguez et al were applied to data obtained before 3 years of age to detect active asthma during one of the surveys between 6 and 13 years of age. The ORs for active asthma at 11 years were 2.6 for the loose and 4.3 for the stringent indices, and for active asthma during at least one of the surveys (6-13 years) of 3.9 and 7.1, respectively. ${ }^{8}$ In the present population, the ORs of current asthma for children with a severity score above 5 compared with children with no $\mathrm{BO}$ was markedly higher (7.9) than when we applied the loose and stringent (6.4) indices suggested by CastroRodriguez et al. Furthermore, the positive predictive value (of current asthma) of the severity score at 2 years of $>5$ (as suggested by the ROC analysis) was 54.3, compared with 47.8 when applying the stringent index. Thus we believe that our simple scoring system based solely on a history of $\mathrm{OAD}$ by 2 years may be as suitable to predict current asthma 8 years later as the score which includes heredity and invasive laboratory tests, as well as a history of rhinitis with uncertain aetiology at this age. ${ }^{78}$

The predictability of our severity score at 2 years classified by current asthma at 10 years was demonstrated by a statistically significant area under the curve by ROC analysis. Such ROC curve analysis and calculation of sensitivity, specificity as well as positive and negative predictive values are used to assess the applicability of a diagnostic test. In both ours and the study by Castro-Rodriguez and coworkers, ${ }^{8}$ assessment of positive and negative predictive values demonstrated that scoring systems can be used to identify children with a high and low risk of active asthma in later childhood, and consequently that information obtained in early life may have a prognostic value for the patient. Applicability of the stringent and loose indices suggested by Castro-Rodriguez et al was demonstrated in a different study population than their own, whereas this remains to be demonstrated for our severity score. As both sets of scores include assessment of severity through the first years of life, they may to some extent corroborate each other and can be used with reasonable accuracy to predict which symptomatic infants are likely to have asthma during their school years.

The low predictability of the 12 month severity score in the present study may reflect the fact that many patients had not yet developed manifestations of obstructive airways disease. Also, the score at this point was constructed from data obtained in questionnaires only, with less detailed information than that obtained during parental interviews at 2 years.

Predictability of later disease may influence management strategies, and benefits of early anti-inflammatory treatment of asthma in school children has been discussed. ${ }^{20}$ However, recent randomised double blind placebo controlled trials in infancy, ${ }^{21}$ from infancy to 5 years of age ${ }^{22}$ and from preschool age ${ }^{23}$ have demonstrated improved symptom control and lung function during inhaled corticosteroid treatment, but not after cessation of such treatment. Thus decisions for corticosteroid treatment to improve long term outcome of asthma in individual patients based on prognostic scores may be inappropriate, whereas scores to suggest prognosis may be useful to identify children with special needs for closer follow-up and management of disease.

In the present study, parental atopy, atopic dermatitis as well as allergic skin sensitisation assessed at 2 years did not influence the risk of current asthma based on the severity score, and adjusted and unadjusted odds ratios were almost similar. However, the $\mathrm{rBO}$ children had a family history of atopy at 2 years similar to that in the studies by Castro-Rodriguez et $a l^{8}$ and Clough et al, 7 whereas allergic skin sensitisation at 2 years, positive in very few children in the present study, was not assessed in the latter studies.

Table 5 Distribution of patients according to severity score at 2 years and bronchial responsiveness to methacholine $\left(\mathrm{PD}_{20}\right.$ methacholine) at 10 years of age

\begin{tabular}{llll}
\hline & $\mathbf{P D}_{\mathbf{2 0}}<\mathbf{1} \boldsymbol{\mu \mathrm { mol }}(\%)$ & $\mathbf{P D}_{\mathbf{2 0}} \mathbf{1}-<\mathbf{8} \boldsymbol{\mu m o l}(\%)$ & $\mathbf{P D}_{\mathbf{2 0}} \geqslant \mathbf{8} \boldsymbol{\mu m o l}(\%)$ \\
\hline Severity score $0(\mathrm{n}=211)$ & $18(8.5)$ & $66(31.3)$ & $127(60.2)$ \\
Severity score $>5(\mathrm{n}=90)$ & $20(22.2)$ & $30(33.3)$ & $40(44.5)$ \\
\hline
\end{tabular}

Significantly more patients with severity score $>5$ had severe bronchial responsiveness $\left(\mathrm{PD}_{20}\right.$ methacholine $\left.<1 \mu \mathrm{mol}\right)$ $\left(\chi^{2}=15.3304, p=0.0041\right)$. 


\section{Strengths and limitations of the present study}

In the present study, current asthma was defined by combining clinical diagnosis, current symptoms and current medication and an objective measure of exercise induced bronchoconstriction increasing the likelihood of selecting children with true persistent asthma and ongoing inflammatory airways disease. ${ }^{14}$

The prospective design with a longitudinal birth cohort study of children in a nested case control study and an 8 year follow-up rate of $89 \%$ limits the risk of recall bias at 10 years. Furthermore, the main outcome was current asthma at 10 years of age with symptoms present during the last year only which again minimises recall bias for the last 12 months. The study consequently focused on clinical presentation at the time of investigations (2 and 10 years), rather than the retrospective categorisation of "wheezing" phenotypes such as early onset transient wheeze, persistent wheeze and late onset wheeze. ${ }^{3}$

In conclusion, we have reported that a simple scoring system based on severity and frequency of $\mathrm{OAD}$ during the first 2 years of life predicted a higher risk for current asthma at 10 years of age. The simplicity of the symptom score renders it generally applicable for early identification of children at high risk of persistent asthma, with the possibility of subsequent consideration of relevant management strategies.

Acknowledgements: We are grateful to the children and parents participating in the study and to the research team involved in the clinical investigations of the follow-up study, especially to Solveig Knutsen, Ingebjørg Coward, Jorun Wikstrand, Trine Stensrud and Anne Cathrine Mork Wik.

Funding: Grants from Norwegian Research Council, University of Oslo, the Norwegian Foundation for Health and Rehabilitation, Ullevål University Hospital, Health East (Regional Health Authority), the Norwegian Association of Asthma and Allergy, Voksentoppen, the Kloster Foundation and AstraZeneca.

Competing interests: None.

\section{REFERENCES}

1. Martinez FD, Wright AL, Taussig LM, et al. Asthma and wheezing in the first six years of life. The Group Health Medical Associates. N Engl J Med 1995;332:133-8.

2. Carlsen KH. What distinguishes the asthmatic amongst the infant wheezers? Pediatr Allergy Immunol 1997;8(10 Suppl):40-5.
3. Stein RT, Martinez FD. Asthma phenotypes in childhood: lessons from an epidemiological approach. Paediatr Respir Rev 2004;5:155-61.

4. Lenney W. The burden of pediatric asthma. Pediatr Pulmonol 1997;15(Suppl):13-16.

5. Godden DJ, Ross S, Abdalla M, et al. Outcome of wheeze in childhood. Symptoms and pulmonary function 25 years later. Am J Respir Crit Care Med 1994;149:106-12.

6. Håland G, Lødrup Carlsen $K C$, Sandvik $L$, et al. Reduced lung function at birth increases risk of asthma at 10 years of age. N Engl J Med 2006;355:36-43.

7. Clough JB, Keeping KA, Edwards LC, et al. Can we predict which wheezy infants will continue to wheeze? Am J Respir Crit Care Med 1999;160(5 Pt 1):1473-80.

8. Castro-Rodriguez JA, Holberg CJ, Wright AL, et al. A clinical index to define risk of asthma in young children with recurrent wheezing. Am J Respir Crit Care Med 2000;162(4 Pt 1):1403-6.

9. Reijonen TM, Kotaniemi-Syrjanen A, Korhonen K, et al. Predictors of asthma three years after hospital admission for wheezing in infancy. Pediatrics 2000;106:1406-12.

10. Dodge R, Martinez FD, Cline MG, et al. Early childhood respiratory symptoms and the subsequent diagnosis of asthma. J Allergy Clin Immunol 1996;98:48-54.

11. Lodrup Carlsen KC. The environment and childhood asthma (ECA) study in Oslo: ECA-1 and ECA-2. Pediatr Allergy Immunol 2002;13(Suppl 15):29-31.

12. Devulapalli CS, Haaland G, Pettersen M, et al. Effect of inhaled steroids on lung function in young children: a cohort study. Eur Respir J 2004;23:869-75.

13. Aas K, Belin L. Standardization of diagnostic work in allergy. Int Arch Allergy App/ Immunol 1973;45:57-60.

14. Lodrup Carlsen KC, Haland G, Devulapalli CS, et al. Asthma in every fifth child in Oslo, Norway: a 10-year follow up of a birth cohort study. Allergy 2006;61:454-60.

15. Quanjer PH, Tammeling GJ, Cotes JE, et al. Lung volumes and forced ventilatory flows. Report Working Party Standardization of Lung Function Tests, European Community for Steel and Coal. Official Statement of the European Respiratory Society. Eur Respir J 1993;16(Suppl):5-40.

16. Zapletal A, Samanek M, Paul T. Lung function in children and adolescents. Methods, reference values. Prog Respir Res 1987;22:113-18.

17. Crapo RO, Casaburi R, Coates AL, et al. Guidelines for methacholine and exercise challenge testing-1999. This official statement of the American Thoracic Society was adopted by the ATS Board of Directors, July 1999. Am J Respir Crit Care Med 2000;161:309-29.

18. Carlsen KH, Engh G, Mork M. Exercise-induced bronchoconstriction depends on exercise load. Respir Med 2000;94:750-5.

19. Hosmer DW Jr, Lemeshow S. Applied logistic regression, 2nd Edn. New York: John Wiley \& Sons, Inc, 2000.

20. Agertoft L, Pedersen S. Effects of long-term treatment with an inhaled corticosteroid on growth and pulmonary function in asthmatic children. Respir Med 1994;88:37381.

21. Bisgaard $\mathbf{H}$, Hermansen $M N$, Loland L, et al. Intermittent inhaled corticosteroids in infants with episodic wheezing. N Engl J Med 2006;354:1998-2005.

22. Murray CS, Woodcock A, Langley SJ, et al. Secondary prevention of asthma by the use of Inhaled Fluticasone propionate in Wheezy INfants (IFWIN): double-blind, randomised, controlled study. Lancet 2006;368:754-62.

23. Guilbert TW, Morgan WJ, Zeiger RS, et al. Long-term inhaled corticosteroids in preschool children at high risk for asthma. N Engl J Med 2006;354:1985-97.

\section{BNF for Children 2006, second annual edition}

In a single resource:

- guidance on drug management of common childhood conditions

- hands-on information on prescribing, monitoring and administering medicines to children

- comprehensive guidance covering neonates to adolescents

For more information please go to bnfc.org. 